\title{
Oportunidades do Mecanismo de Desenvolvimento Limpo para solução do Destino Final de Resíduos Sólidos Urbanos - o Caso do Distrito Federal
}

\author{
BEZERRA, Maria do Carmo de Lima
}

\begin{abstract}
Resumo
O trabalho analisa as oportunidades financeiras criadas pelo MDL - mecanismo de desenvolvimento limpo, estabelecido no âmbito do Protocolo de Kyoto em 1997, que possibilitou a venda de créditos de carbono. $O$ encerramento de lixões é uma das ações que podem ser beneficiadas por este mecanismo, gerando recursos para recuperação ambiental de suas áreas e/ou implantação de aterros sanitários. $O$ caso em análise trata de um projeto que adotou o MDL para apoiar o fechamento do lixão do Jóquei Club em Brasília e a abertura de um novo aterro sanitário no Distrito Federal. A proposta foi apoiada por inventário do potencial econômico dos gases do antigo lixão e da geração futura no aterro, e pela análise de viabilidade econômica em termos de adesão à venda de créditos de carbono. A discussão está ancorada na necessidade de revisão de padrões tecnológicos na infraestrutura urbana que contribuam para melhorias sanitárias das cidades e redução de gases de efeito estufa como enfrentamento às mudanças climáticas.
\end{abstract}

Palavras-chave: Aterro sanitário; Créditos de carbono; Mudanças Climáticas.

\begin{abstract}
This paper discusses the financial opportunities created by the CDM Clean Development Mechanism established under the Kyoto Protocol in 1997, which allows the sale of the carbon credits. The shutting down of garbage dumps is one of the actions that can be beneficiated from this mechanism, generating resources for the environmental recuperation of the areas of the dumps and / or deployment of landfills, environmental improvement actions for the cities. The analyzed subject is a project that adopted the CDM to support the shutting down of the Jockey Club garbage dump in Brasilia and the opening of a new landfill in the Federal District. The proposal was supported by inventory of the economic potential of the former garbage dump gases and the future generation of a landfill, and through the analysis of economic feasibility in terms of adherence to the sale of carbon credits. The discussion is based on the need for the revision of technological standards in urban infrastructure that contribute to healthful by cities and on the reduction of the greenhouse gases to deal with climate change.
\end{abstract}

Keywords: Landfill; Carbon credits; Climate changes. 


\section{Introdução}

O nível de contribuição das cidades com Gases de Efeito Estufa - GEE depende de uma variedade de fatores como, por exemplo, a forma urbana, a densidade populacional, o sistema de transporte, o design de suas edificações e as tecnologias utilizadas. (The World Bank, 2011).

As respostas das cidades frente às mudanças climáticas colocam desafios que requerem ações de caráter técnico, político-institucional, econômico e social. Em consonância com a Conferência das partes - COP3 de 1997', essas ações podem ser de diferentes naturezas e envolvem estratégias de três tipos: (i)mitigação de impactos das mudanças climáticas na estrutura urbana; (ii) ações de adaptação das infraestruturas às novas condições climáticas; e, (iii) redução dos gases de efeito estufa, responsáveis pelas mudanças climáticas.

Os impactos desencadeados nas cidades estão atrelados à sua localização, característica geográfica e existência de áreas de risco decorrentes das mudanças climáticas - assentamentos informais, encostas e áreas propensas a inundações, por exemplo. Esses aspectos determinarão se as cidades podem ser afetadas e em que grau será este impacto.

De acordo com a UN-HABITAT, 2011, entre os temas nos quais os planejadores urbanos podem apoiar e conduzir suas atividades estão: uso do solo, planejamento ambiental, gestão de águas pluviais e residuais, planos e projetos de transporte, programas de gestão de resíduos sólidos, gestão de fornecimento de água, programas de saúde comunitária e programas de educação pública.

As medidas de mitigação e redução têm sido as mais adotadas nas cidades até o momento em todos os tipos de programas de enfrentamento às mudanças climáticas e concentram-se, prioritariamente, nos setores de desenvolvimento e desenho urbano, infraestruturas urbanas, transporte e projetos de sequestro de carbono. A realização de um inventário de fontes e quantificação das emissões dos gases de efeito estufa é uma etapa primordial para qualquer ação; sem ele não é possível pensar em definir programas e projetos para serem inseridos no planejamento da Cidade. (Centro Clima/COPPE, 2011 in BID, 2011)

Em função de sua importância frente às três estratégias acima referidas, o setor de saneamento ambiental urbano passou a contar com a atenção de projetos de agências internacionais dedicadas ao desenvolvimento urbano e socioambiental, além de Governos e pesquisadores do planejamento urbano. Os estudos sobre resíduos sóli- dos têm-se salientado, tanto por sua contribuição às mudanças climáticas devidas à emissão de gases de efeito estufa na fase de deposição dos resíduos, quanto pela utilização dos mecanismos desenvolvimento limpo.

\section{Desafios tecnológicos do Saneamento Ambiental frente às mudanças climáticas}

Independentemente dos cenários das mudanças climáticas, o setor de saneamento ambiental já encontra enormes desafios no sentido da universalização da prestação de serviços e da manutenção de padrões aceitáveis de qualidade.

As medidas de redução dos GEE provenientes da ausência e/ou presença da infraestrutura de diversos componentes do setor pedem a discussão da revisão dos paradigmas tecnológicos que vêm amparando as soluções de infraestrutura em nossas cidades.

As soluções normalmente apresentadas não têm respondido às necessidades de saneamento nas cidades dos países em desenvolvimento onde a urbanização está ocorrendo de forma acelerada, sendo uma das razões dos grandes déficits existentes. Em outras palavras, elas não foram capazes de acompanhar as crescentes demandas, tanto pelo aumento populacional, quanto pela expansão do território urbano, por constituirem-se soluções universais apresentadas como verdade única para o enfrentamento das necessidades.

Em decorrência disto, pensar hoje em adaptação e mitigação de impactos das mudanças climáticas neste setor nos coloca frente à decisão crucial de revisão das tecnologias tradicionalmente adotadas.

\subsection{Discussão sobre o papel das soluções tecnológicas}

Para que o avanço na discussão sobre a revisão de padrões tecnológicos de infraestrutura urbana faz-se necessária a ampliação do conceito de tecnologia, isto é, é necessário entendê-la como o conjunto das técnicas e suas implicações econômicas e socioambientais ${ }^{2}$. Pensar a tecnologia apenas como instrumento, com o qual se executam decisões políticas, é uma simplificação que reduz o papel das decisões tecnológicas sobre a gestão do território.

A escolha de um padrão tecnológico incorpora em si mesma uma decisão política, e as decisões políticas são tomadas a partir das informações disponíveis sobre as opções tecnológicas, bem como da avaliação de sua eficácia que a população a ser atendida faz. 
É importante considerar que a satisfação da população é formulada quase sempre em função das tecnologias por ela conhecidas e, em particular, daquelas que se articulam com a ideologia dominante - onde o poder público desempenha um papel significativo, especialmente junto às populações mais pobres. A tendência da população de baixa renda, quando há um espaço para manifestação sobre suas expectativas em relação a melhorias urbanas, é expressar o desejo de possuir as mesmas soluções adotadas em áreas centrais e privilegiadas das cidades.

Desta forma, a revisão de paradigmas ${ }^{3}$ tecnológicos convencionais não deve ocorrer apenas em função do custo, mas em decorrência de sua adequação/inadequação às especificidades de cada local - tanto em termos sociais quanto ambientais. Esta revisão deve também ser precedida de amplo programa informativo sobre funcionamento, perdas e ganhos para a população. Infelizmente, em países em desenvolvimento predomina a ideia de revisão de padrão tecnológico na área de infraestrutura urbana apenas como uma necessidade de baixar custos para atendimento às áreas de mais baixa renda ${ }^{4}$.

Para exemplificar como as soluções tradicionais estão distantes da realidade da urbanização brasileira em termos de resíduos sólidos, de acordo a Pesquisa Nacional de Saneamento Básico-PNSB, 2008, o aterro sanitário construído pelo sistema tradicional, em termos técnicos e de modelo gestão, tem sido uma solução para apenas $36.6 \%$ do total de resíduos coletados - contra $41 \%$ nos aterros controlados (Iixões adaptados com algum controle ambiental); 0,4\% incinerados; $3,5 \%$ em centros de triagem; e $18.5 \%$ em outras áreas (entendidas como situação sem controle).

Atualmente, as emissões dos gases de efeito estufa - GEE relacionados diretamente com o setor de saneamento correspondem a $4 \%{ }^{5}$ da emissão total, e as tecnologias convencionais de tratamento de resíduos constituem uma das contribuições. Evitar ou capturar esses GEE são tanto uma preocupação ambiental, quanto uma oportunidade econômica para as municipalidades que possuem a competência de gestão do setor.

A ampliação da consciência social sobre a necessidade de tratamento adequado dos resíduos aumentou na última década em decorrência de programas ambientais. Por outro lado, cresceu o interesse econômico na reciclagem, que passou a ser economicamente viável, em virtude do aumento do custo de algumas matérias primas. Esses dois fatores criaram um ambiente favorável à introdução de tecnologias que avancem na solução do problema.
Certamente a solução do aterro sanitário, não deve ser descartada do rol de soluções que devem compor o destino final dos resíduos sólidos urbanos, mas há que considerar adaptações aos modelos de engenharia pensados no século passado, não apenas em termos de tecnologia operacional, mas também de gestão, ambas beneficiadas com a articulação de outros componentes do saneamento. Um exemplo disto são as estações de tratamento de esgotos e o aproveitamento de gases como fontes de energia necessárias ao seu próprio funcionamento ou complemento às necessidades da cidade. Tudo isto contribui para o enfrentamento das mudanças climáticas em áreas urbanas e não somente as adaptações neste setor que geram recursos adicionais para crise financeira em que vivem as cidades..

\subsection{Legislação de resíduos sólidos e mudanças climáticas no Brasil}

O atual contexto legal do setor do saneamento no Brasil que dispõe de diretrizes nacionais estabelecidas pela Lei Federal $n^{\circ} 11.445 / 2007$ incentiva o uso de tecnologias apropriadas, a articulação entre a política de desenvolvimento urbano e a ambiental, e preconiza a universalização do saneamento ambiental - entendido como o abastecimento de água, o esgotamento sanitário, a drenagem e a coleta e o tratamento de resíduos sólidos.

A Política Nacional de Resíduos Sólidos, Lei Federal 12.305/2010, também prevê a elaboração de Planos Estaduais de Gestão Integrada de Resíduos Urbanos, que devem conter as soluções de infraestrutura para o equacionamento do problema relacionado à disposição inadequada de resíduos sólidos e uso de tecnologia para a eliminação de lixões, incentivo à compostagem e reciclagem, bem como o tratamento adequado do metano produzido. Por outro lado, a Política Nacional sobre Mudanças do Clima, Lei Federal $12.187 / 2009$, contém metas para aumento da reciclagem de resíduos sólidos para $20 \%$ até o ano de 2015 e de incentivo ao aproveitamento energético do biogás de aterro sanitário ${ }^{6}$.

\section{As relações entre gestão de resíduos sólidos e mudanças climáticas}

A tecnologia convencional adotada na maioria dos aterros sanitários no Brasil vem sendo a de coletar e queimar o gás somente através de um sistema passivo de ventilação, sem nenhuma queima sistemática e monitorada. $\mathrm{O}$ metano é emitido naturalmente para a atmosfera através dos drenos existentes, e parte do gás é destruída devido a questões de odor e segurança, o que libera emissões dos gases efeito estufa. 
A relevância do tema de resíduos para o aquecimento global e para as mudanças climáticas se deve ao tratamento anaeróbico dispensado aos resíduos sólidos e aos efluentes líquidos, que são fonte geradora de metano $\left(\mathrm{CH}_{4}\right)$, gás que retém cerca de vinte vezes mais calor na atmosfera que o dióxido de carbono $\left(\mathrm{CO}_{2}\right)^{7}$.

Um aterro de resíduos sólidos pode ser considerado como um reator biológico onde as principais entradas são os resíduos e a água e as principais saídas são os gases e o chorume. A decomposição da matéria orgânica ocorre por dois processos: o primeiro é de decomposição aeróbica, que ocorre normalmente no período de deposição do resíduo. Após este período, o segundo processo, é a redução do $\mathrm{O}_{2}$ presente nos resíduos que dá origem ao processo de decomposição anaeróbica.

O aterro é composto por vários gases, alguns presentes em grandes quantidades como o metano e o dióxido de carbono, e outros em quantidades em traços. Os gases presentes nos aterros de resíduos incluem o metano $\left(\mathrm{CH}_{4}\right)$, o dióxido de carbono $\left(\mathrm{CO}_{2}\right)$, a amônia $\left(\mathrm{NH}_{3}\right)$, o hidrogênio $\left(\mathrm{H}_{2}\right)$, o gás sulfídrico $\left(\mathrm{H}_{2} \mathrm{~S}\right)$, o nitrogênio $\left(\mathrm{N}_{2}\right)$ e o oxigênio $\left(\mathrm{O}_{2}\right)$. O metano e o dióxido de carbono são os principais gases provenientes da decomposição anaeróbica dos compostos biodegradáveis dos resíduos orgânicos. A distribuição exata do percentual de gases depende do tempo de operação de cada aterro, além de suas condições de gerenciamento.

Geralmente a geração de biogás inicia-se após a disposição dos resíduos sólidos, encontrando-se registros de metano ainda nos primeiros três meses após a disposição, podendo continuar por um período de 20,30 ou até mais anos depois do encerramento do aterro. $O$ gás proveniente dos aterros contribui consideravelmente para o aumento das emissões globais de metano. As estimativas das emissões globais de metano provenientes dos aterros oscilam entre 20 e 70 Tg/ano, enquanto que o total das emissões globais pelas fontes antropogênicas equivale a $360 \mathrm{Tg} / \mathrm{ano}$, o que indica que os aterros podem produzir cerca de 6 a $20 \%$ do total de metano (IPCC, 1995).

Segundo o Primeiro Inventário Nacional de Emissões Antrópicas de Gases de Efeito Estufa realizado pelo Governo Federal em 2005, as emissões de metano por resíduos sólidos no Brasil para o ano de 1990 foram estimadas em $618 \mathrm{Gg}$, aumentando para $677 \mathrm{Gg}$ no ano de 1994. As emissões de metano geradas no tratamento dos resíduos líquidos de origem doméstica e comercial foram estimadas em $39 \mathrm{Gg}$ para o ano de 1990, subindo para 43 Gg em 1994.

Aqui vale destacar uma contradição: o aterro sanitário tradicional pode ser uma solução de des- tino final mais seguro do ponto de vista sanitário, mas emite GEE contribuindo com as mudanças climáticas. Este é o ponto onde se faz necessária uma conjugação de esforços de adaptação tecnológica para que os dois objetivos sejam conjugados.

O aproveitamento energético do biogás produz, pela degradação dos resíduos, uma forma de energia útil tal como eletricidade, vapor, combustível para caldeiras ou fogões, combustível veicular ou para abastecer gasodutos com gás de qualidade. Existem diversos projetos de aproveitamento energético no Brasil, como nos aterros Bandeirantes e São João, no município de São Paulo, que já produzem energia elétrica.

O MDL propicia a obtenção de recursos pela venda de créditos de carbono, incentiva a captura do metano $\left(\mathrm{CH}_{4}\right)$, e viabiliza seu aproveitamento energético. Desta forma, além de se conseguir aproveitar os resíduos para gerar energia, ainda evita-se o lançamento de GEE na camada de ozônio e seu consequente impacto. É aí que entram os projetos de MDL em aterros.

Os mecanismos de desenvolvimento limpo - MDL previstos no Protocolo de Kyoto apresentam-se como a alternativa promotora de proteção ambiental com possibilidades de sustentação econômico-financeira aos projetos de tratamento de resíduos. É verdade que projetos para acesso ao MDL requerem adoção das tecnologias mais caras do que o simples aterramento dos resíduos. Entretanto, se esses projetos forem analisados em uma perspectiva integradora de processos de melhoria ambiental com otimização energética, podem transformar as fontes de despesas em fontes de investimento.

\section{Mecanismo de Desenvolvimento Limpo - MDL}

Na busca de conciliar a ação local com o pensamento global, desde 2004 o Ministério do Meio Ambiente e 0 Ministério das Cidades desenvolvem o "Projeto para Aplicação do Mecanismo de Desenvolvimento do Limpo (MDL) na Redução de Emissões em Aterros de Resíduos Sólidos" financiado pelo Banco Mundial por meio do fundo PHRD (Policy and Human Resources Development Fund) que opera com recursos do Governo Japonês.

Em 2007 e 2008, o projeto capacitou cerca de 400 agentes locais e técnicos de prefeituras, para elaboração de Planos de Gerenciamento Integrado de Resíduos Sólidos e para aplicação do Mecanismo de Desenvolvimento Limpo - MDL em projetos de captação e tratamento de gases gerados em locais de destinação final de resíduos. 


\subsection{Projetos de aterros sanitários com captura de carbono}

Como referido anteriormente, a primeira etapa para acesso ao MDL é a realização de um inventário dos gases para conhecer sua viabilidade econômica. O projeto fundamentado nesta viabilidade é enviado para registro, que é pré-requisito para o monitoramento, verificação, certificação e emissão de RCEs (Reduções Certificadas de Emissões), unidade monetária do MDL. Com o registro, o aterro pode fazer as medições de redução de $\mathrm{CO}_{2}$ equivalente para a venda do crédito de carbono. As medições passam por monitoramento para ver se houve redução de $\mathrm{CO}_{2}$ equivalente e os relatórios das auditorias são enviados para análise pelo Conselho Executivo do MDL. Somente após a medição são emitidas as RCEs para a venda do crédito.

\section{Aterros novos: 0 caso de Nova Iguaçu}

0 Brasil foi pioneiro ao ter o primeiro projeto de MDL registrado pela ONU, o Projeto Novagerar, da empresa S. A. Paulista, que prevê a venda de crédito de carbono a partir dos gases gerados em aterro sanitário em Nova Iguaçu, na Baixada Fluminense. 0 modelo de negócio predominante no setor, prevê que o Município faça a concessão da exploração do aterro à iniciativa privada, recebendo em troca participação no projeto.

\section{Encerramento de aterros: 0 caso Bandeirantes}

Um dos exemplos mais conhecidos de projetos de MDL implantados em Aterro Sanitário é o caso do Aterro Sanitário Bandeirantes, localizado em Perus, na região metropolitana de São Paulo. Com uma área total de $1.400 .000 \mathrm{~m}^{2}$, o Aterro Bandeirantes está desativado desde março de 2007 tendo operado durante 28 anos e recebido, até 2006 , cerca de 36 milhões de toneladas de resíduos. A captação do biogás gerado no aterro foi iniciada em 2004, após uma série de estudos preliminares sobre a viabilidade do projeto e a instalação de uma usina termelétrica a biogás em 2003, onde 0 gás captado no aterro é tratado (retirada a umidade e feita uma pré-filtragem) e depois transformado em energia. 0 Aterro Bandeirantes possui capacidade para gerar aproximadamente 170 mil MWh de energia elétrica por ano e possibilitou, até então, a comercialização pela prefeitura de São Paulo de 1.262.793 RCE's (Reduções Certificadas de Emissão), ou créditos de carbono, sendo que cada crédito corresponde a 1 tCOe (tonelada de carbono equivalente) que deixaram de ser lançados para a atmosfera (COELHO, 2008).

\subsection{Crise econômica mundial e a viabilidade do MDL}

O mercado regulado de crédito de carbono feito pelas empresas com meta de redução de emissões determinada pelo Protocolo de Kyoto - encolheu. Segundo dados mais recentes, com a crise econômica pós 2008 , o volume de tonelada de carbono equivalente vendida diminuiu de 7,4 milhões em 2009, para 6,7 milhões em 2010. Em valores, a queda foi de US\$ 128 milhões para US\$ 124 milhões no mesmo período. Já o mercado voluntário, resultado de acordos bilaterais, e que não servem para cumprir as metas de Kyoto, cresceu no mesmo período: de 98 milhões de toneladas de carbono equivalente vendidas, para 131 milhões; passando de US\$ 415 milhões em 2009, para US\$ 424 milhões em 2010.

A crise econômica internacional de 2008 levou a uma redução das emissões de GEE em decorrência da baixa produção industrial e, por conseguinte, levou a uma diminuição do interesse na compra de créditos de carbono.

Para se ter uma ideia das oscilações de preços, em setembro de 2007 a prefeitura de São Paulo conseguiu vender, em leilão, seus créditos de carbono por $€ 16,20$ a tonelada e, em 2008, num segundo leilão, o preço foi de $€ 19,20$ a tonelada, bem acima do valor hoje negociado pela Caixa $(€ 6,75)$.

O número de projetos brasileiros certificados para vender créditos de carbono caiu em 2011, depois de uma leve recuperação em 2010. Foram registrados pela Organização das Nações Unidas (ONU) apenas 14 projetos de redução de emissões em 2011, frente a 20 em 2010. A queda no número de projetos, cujo pico foi de $81 \mathrm{em}$ 2006, começou em 2009, com a crise financeira internacional.

Além da crise econômica que fez reduzir o interesse na compra dos créditos, foi a validade do Protocolo de Kyoto que acabou sendo estendida até $2017^{8}$.

Apesar desse cenário, algumas iniciativas no Brasil dão sinais de que a perspectiva é de recuperação desse mercado no País. Uma delas é a disposição do governo brasileiro de criar um mercado interno de redução de emissões, o que permitiria a empresas brasileiras comprarem crédito.

Assim, a revisão dos acordos de Kyoto e as articulações necessárias entre a Política de Saneamento e Política Urbana do País com os mecanismos econômicos são essenciais para alavancar as metas definidas pelas legislações do clima, do saneamento e ambientais afetas aos resíduos sólidos. Cabe aos planejadores urbanos maior 
intimidade com esses mecanismos para garantir a melhoria ambiental de nossas cidades.

\section{Caracterização da área de estudo, o Distrito Federal}

O Distrito Federal, criado há 50 anos para abrigar a Capital da República, está localizado no centro geográfico do País. Sua concepção urbanística tentou evitar o desenvolvimento de uma única mancha urbana optando pela implantação de vários núcleos urbanos periféricos, dos quais a cidade de Brasília é a área central. O Distrito Federal experimentou um intenso crescimento ao longo destes anos, passando de 140.000 habitantes em 1960, para os atuais 2,5 milhões de habitantes. Os diversos núcleos urbanos foram implantados em diferentes períodos e possuem as seguintes características:

- A cidade de Brasília, patrimônio mundial da humanidade, situa-se às margens do Lago Paranoá e conta com $15,5 \%$ da população do Distrito Federal. Abriga a sede do poder federal e local, dispõe de habitações coletivas com toda infraestrutura implantada no padrão convencional e duas grandes áreas de habitações individuais compostas pelos bairros do Lago Norte e Lago Sul.

- As outras 30 "cidades satélites", cuja população varia de 350 mil habitantes, maiores que a área central, a 30 mil habitantes ou menos, foram implantadas em diferentes períodos. Hoje $o$ atendimento de abastecimento d'água e esgotamento sanitário com tratamento está universalizado nas áreas regularizadas, e vem sendo implantado nas áreas irregulares e em processo de regularização, sejam de baixa ou média renda.

Assim, em termos de abastecimento de água e esgotamento sanitário, o Distrito Federal é uma das unidades da Federação mais bem atendidas, contando com $90,54 \%$ de coleta e tratamento de esgotos e $97,57 \%$ de abastecimento d'água.

Em relação ao sistema de drenagem, possui sistema implantado em todas as áreas regulares, contando com 26 áreas de risco ${ }^{9}$ de inundação em pontos específicos, quase todos nas áreas irregulares. Possui um recente Plano de Drenagem Urbana $^{10}$ elaborado em 2009 que prevê, dentre outras, solução técnica para as localidades onde os problemas estão associados a ocupação de áreas de fragilidade ambiental.

Em oposição aos outros componentes do saneamento, a gestão dos resíduos sólidos conta com todas as mazelas possíveis: ausência de planejamento e de um órgão com capacidade técnica instalada, problemas operacionais e financeiros na coleta, e inexistência de qualquer destino final com segurança ambiental ${ }^{11}$.

O caso em estudo está focado no destino final que o Distrito Federal realiza, lançando seus resíduos $^{12}$ em um aterro controlado - nome dado aos lixões que possuem algum controle ambiental. Grande parte da população clama por uma solução, motivada pela localização do aterro, que está às margens do Parque Nacional de Brasília e do córrego Vicente Pires, um dos tributários do lago Paranoá, e pela total ausência de controle sanitário associado ao esgotamento da área. A questão social dos aproximadamente 2 mil catadores que operam no Lixão é outro tema preocupante que merece tratamento de seus diversos aspectos em outro estudo.

\subsection{Desafios da implementação de um novo destino final de resíduos sólidos no DF}

O desafio de implantar um aterro sanitário em Brasília remonta, também, ao início da década de 1990 - mesmo período em que se discutiam outras revisões tecnológicas do setor de saneamento no DF, como foi o caso do esgoto condominial ${ }^{13}$. Alguns estudos técnicos foram realizados à época, mas a iniciativa não se viabilizou devido aos seguintes fatores: (i) dificuldade em selecionar uma área adequada; (ii) ausência de um trabalho de consciência ambiental junto à sociedade e, internamente, ao próprio governo; (iii) existência de um órgão gestor desestruturado e despreparado tecnicamente; e, (iv) ausência de recursos orçamentários, uma vez que à época contava-se apenas com orçamento público.

Hoje, além da saturação da área onde está sendo depositado o lixo, existem outros fatores que favorecem a sua desativação, tais como: (i) a existência de áreas urbanizadas em suas proximidades; (ii) ampliação da consciência ambiental; e (iii) um quadro jurídico-institucional favorável à captação de investimentos em serviços públicos por meio de parcerias entre governo e iniciativa privada.

Entretanto, a fragilidade institucional do órgão gestor se mantém, sendo o maior risco para o avanço das soluções, pois não se dispõe de uma estrutura de governo capaz de conduzir as discussões com as diferentes forças de mercado associadas ao tema, que hoje detêm um peso considerável.

O fato determinante para que o assunto do encerramento do lixão voltasse à pauta política com alguma viabilidade de mudança das condições que já estavam postas a mais de duas décadas, foi o Projeto de Regularização Fundiária da Vila Estrutural, área contígua ao aterro "controlado'. 
Entre 2006 e 2009, a área ocupada por cerca de 45.000 habitantes que se instalaram inicialmente em torno da catação de lixo foi urbanizada, com instalação de todos os serviços de infraestrutura urbana. As condições do licenciamento ambiental do assentamento e o contrato de financiamento realizado entre o GDF e o Banco Mundial colocaram como obrigação o encerramento da operação do aterro controlado existente, como definição de solução técnica para a gestão do destino final de resíduos.

A possibilidade de uma equipe técnica atualiza$\mathrm{da}^{14} \mathrm{com}$ as possiblidades existentes no setor permitiu, em tempo curto, o alcance de solução com viabilidade técnica, mas especialmente financeira.

\subsection{Características da solução definida com uso do MDL}

O projeto de um novo aterro sanitário foi elaborado entre 2008 e 2009, e teve os estudos marcados pela preocupação com a inclusão social dos catadores do lixão, por meio da coleta seletiva (onde se previa a instalação de um centro de triagem em área do projeto da Vila Estrutural), pelo aproveitamento dos gases na forma de geração de energia e acesso ao mercado de carbono, visando a viabilização econômica e a recuperação ambiental da área do atual aterro controlado, com o abatimento do custo de implantação do novo aterro.

Foram realizadas pesquisas de campo no lixão e inventário para análise do potencial de gases ${ }^{15}$ que identificaram tanto as áreas a serem exploradas, quanto as que, por não serem interessantes para a exploração de gases, deveriam ser objeto apenas de recuperação ambiental.

O estudo iniciado com pesquisa de campo em janeiro de 2008 foi concluído em setembro do mesmo ano e apresentou os seguintes produtos que ancoraram a viabilidade do encerramento do aterro controlado do Jóquei:

- avaliação técnica sobre as condições de operação do aterro para verificar como podem afetar a produção de biogás e a viabilidade de sua recuperação;

- determinação da geração de gás do aterro e avaliação da recuperação usando um modelo de um sistema de coleta do gás do aterro (LFG) apropriado às condições de operação do aterroç;

- desenvolvimento de um conceito para a captura de biogás e sistema de combustão, incluindo estimativa de capital do sistema e os custos operacionais;

- estimativa dos gases de efeito estufa (GEE) e determinação das possibilidades da redução das emissões para elaboração em análise econômica do projeto;

- estimativa LFG com opções de utilização e de receitas potenciais para equilibrar os custos do projeto como forma de obter receitas para determinar a viabilidade econômica do projeto e para fornecer uma base para a investigação e desenvolvimento de projeto executivo.

A área do novo aterro sanitário que foi definida por meio de avaliação ambiental está fora da zona urbana ou de expansão urbana, nas proximidades das Estações de Tratamento de Esgotos Melchior e Samambaia. Por tudo isto, a área é estrategicamente localizada em relação aos centros produtores de resíduos.

O novo aterro sanitário foi projetado com capacidade de recepção de cerca de 9,5 milhões de toneladas de resíduos de coleta domiciliar, o que corresponde a uma demanda de 1400 toneladas diárias, resultando numa vida útil entre 15 a 18 anos. A proposta possuía usina de queima centralizada de biogás, gerado pelo aterro sanitário, visando o controle de emissões atmosféricas e permitindo auferir benefícios em termos de créditos de carbono, podendo vir a ser integrado com a captação de efluentes gasosos gerados pela ETE Melchior.

A avaliação preliminar de geração de biogás no novo aterro aponta para um cenário de vazões de pico da ordem de $2.500 \mathrm{Nm}^{3} / \mathrm{h}$ de $\mathrm{CH}_{4}$ ao final dos 18 anos de vida útil, auferindo a ordem de 230.000 toneladas equivalentes máximo de Carbono anuais o que, a um valor ${ }^{16}$ de US\$ 12/ tCO${ }_{2}$ equiv., implicaria uma receita máxima da ordem de US\$ 2,76 milhões anuais.

Ao final de 18 anos se projetou um acumulado de cerca de 2,3 milhões de toneladas equivalentes que, sob o mesmo valor de mercado, de US\$ 12/ $\mathrm{tCO}_{2}$, geraria uma receita da ordem de US\$27,6 milhões.

Como mais uma inovação, o projeto previa a participação da CAESB, operadora da ETE, na implantação de uma unidade de tratamento de lodos, vislumbrando a utilização de emissões térmicas da unidade de queima de biogás no processo de secagem e constituição do composto orgânico. Nessas condições, o empreendimento criaria uma Central de Saneamento Ambiental para o DF, conjugando e aplicando as energias geradas de cada unidade no tratamento final dos subprodutos (lodos e chorume), fechando o ciclo ambiental para a região, constituindo-se em modelo de gestão ambiental integrada.

A avaliação preliminar de custos apontava para um valor estimado da ordem de $\mathrm{R} \$ 2,3$ milhões 
para a instalação da usina de queima centralizada e da rede de captação. Os custos de implantação e operação do novo aterro sanitário, pelo período inicialmente preconizado de 18 anos, considerando as avaliações de capacidade volumétrica e à luz de estudos anteriores seria da ordem de $\mathrm{R} \$ 90$ milhões de reais, dos quais cerca de $\mathrm{R} \$ 15$ milhões corresponderiam à implantação inicial do aterro.

O aproveitamento do biogás para geração de energia, já com as perdas embutidas, implicava um valor médio e contínuo de aproximadamente $4 \mathrm{MWh}$, ao longo de um período de 15 anos, que resultaria um custo de cerca de $\mathrm{R} \$ 3.500 .000,00$ complementares.

As duas soluções foram pensadas de forma interligadas, ou seja, a abertura do novo aterro concomitantemente com o fechamento do antigo - que aqui não foi detalhado, mas que possui o mesmo arranjo quanto ao acesso de créditos de carbono e geração de energia. A inserção dos catadores na prévia seleção de resíduos antes do envio ao novo aterro também foi estudada como condição para desativação do antigo aterro controlado.

\section{A realidade da implantação de inovações tecnológicas}

As inovações tecnológicas se viabilizam também a partir de parcerias entre os diversos atores responsáveis pelas políticas públicas e quando o Governo possui um papel de destaque.

Assim, a partir da elaboração de um projeto, sua implementação - que no caso analisado, apesar de todas as vantagens aparentes para o interesse público, ainda não ocorreu - depende de articulação dos interesses de mercado, políticos e de toda uma série de esclarecimentos à burocracia de diversos órgãos afetos às licitações e que precisam enquadrar as inovações nos procedimentos administrativos.

Mais uma vez, a ausência de capacidade técnica no órgão gestor do sistema de resíduos sólidos pesou negativamente. Aqui vale dizer que essa situação ocorre em várias cidades brasileiras, onde é muito desigual a capacidade de articulação das empresas que operam resíduos no país e as estruturas públicas responsáveis pelos contratos de concessão, impossibilitando o exercício do poder público em promover mudanças de gestão.

Tais condições fizeram com que o trabalho encontrasse muitas dificuldades de elaboração na fase de diagnóstico dos gases, quando se necessitava de acesso e informações sobre a área do aterro controlado existente, já que a empresa privada concessionária para a sua operação se sentia ameaçada com as mudanças.
Um exemplo positivo que vem do próprio Distrito Federal, ocorreu na gestão do esgotamento sanitário, quando a CAESB, companhia concessionária local, assumiu como solução de coleta universal para as áreas urbanas em consolidação, o esgoto condominial. Essa solução também começou com trabalho de consultoria externa, e encontrou na CAESB algumas resistências iniciais de seu quadro técnico. Porém, a companhia foi capaz de assimilar a mudança e potencializar vantagens, além de alcançar metas que jamais foram alcançadas por qualquer outra companhia de saneamento no país.

Como já mencionado, no caso em análise houve muita resistência interna ao Governo e as soluções foram quase que concebidas a partir da equipe de consultores do Projeto financiado pelo Banco Mundial. Ocorreram discussões com diferentes atores internos e externos ao governo, mas a inexistência de massa crítica no órgão responsável pela gestão de resíduos e em outras áreas que poderiam ter assumindo este papel dentro do governo, levou à não aderência do mesmo aos interesses locais.

Transcorridos cinco anos, a construção do novo aterro voltou a ser discutida e suas premissas técnicas originais não foram rejeitadas como exploração de gases na recuperação do lixão e aproveitamento na planta nova, apesar de que hoje, como dito anteriormente, as vantagens de venda de créditos de carbono não se colocarem da mesma forma.

Como as empresas locais não atendem, por condições técnicas ou financeiras aos requisitos necessários para o processo licitatório, ainda hoje o modelo de construção e operação está sendo alterado para viabilizar sua construção.

\section{Considerações finais}

Destaca-se a importância de instrumentos econômicos de gestão ambiental, no caso o MDL, como propulsores de novos patamares de meIhoria ambiental.

O gás de aterro é cada vez mais cobiçado por municípios e empresas privadas. As prefeituras veem no biogás a oportunidade de remediar passivos ambientais produzidos por lixões e de garantir fonte de renda com a venda de créditos de carbono e geração de energia.

De um modo geral, o MDL se constitui em oportunidade para os municípios de países emergentes para obtenção de recursos, com resultados para o controle da poluição da água e do solo, ao mesmo tempo em que contribui para o enfrentamento das mudanças climáticas globais. 
O papel do poder público como líder do processo de difusão e implantação das adaptações e inovações tecnológicas é essencial para êxito ou risco em sua assimilação de mudanças nas políticas públicas de infraestrutura.

A prática profissional tem demonstrado que os paradigmas tecnológicos são mais arraigados no meio técnico interno aos órgãos públicos, onde a Universidade desempenha um forte papel formador de opinião, do que no meio político tradicional - que tem como objetivo atender reivindicações da população a um custo mais baixo e em menor espaço de tempo.

O conservadorismo tecnológico estatal tem se manifestado em todas as políticas públicas do setor. A maioria dos técnicos a serviço do setor público tem preferido assumir o grande risco implícito na política de não correr riscos, que abraçar proposta que difiram do paradigma convencional.

\section{Referências}

ALVA, E. 1984. Tecnologias apropiadas, produção de bens e serviços, Revista Brasileira de Tecnologia, vol V, no. 1, p.14-19.

COELHO, Hosmanny M. G. 2008. Aproveitamento Energético do Lixo Urbano e Resíduos Industriais. Lavras: UFLA/FAEPE

Conestoga-Rovers \& Associates. 2008. Pre-Feasibility study for the preparation of landfill gas projects in Latin America and the Caribbean, working paper s/n, Canada.

KUHN. T. 1962. The Structure of Scientific Revolutions, University of Chicago Press. Chicago, Illinois.

TUDELA, K. 1982. Appropriate Technology for Sanitation, Working Paper s/n, FAUUSP, Sao Paulo, November.

IPEA. 2012. Situação social dos estados: Distrito Federal. Disponível em: http://www.ipea.gov. br/portal/images/ stories/PDFs/situacao_social/, acessado em 16 de agosto de 2012.

KAIAMOTO, Luís Sérgio Akira. 2008. Memorial Descritivo do Projeto do Novo Aterro Sanitário do Distrito Federal, Ceppolina Engenheiros Consultores S/S Ltda.

LA ROVERE, Emilio L., SOUSA, Denise, BAPTISTA, Vivien. 2011. COPA 2014: Cidades-Sede e Mudanças Climáticas, Banco Interamericano de Desenvolvimento - BID,

The World Bank, 2010 Cities and Climate Change: An Urgent Agenda Vol. 10, disponível em http://siteresources. worldbank.org/INTUWM/Re-
sources/340232-1205330656272/CitiesandClimateChange.pdf - acessado em 10 de outubro de 2012.

UN-HABITAT, 2011. Cities and Climate Change Global Report on Human Settlements 2011, disponível em http://www.unhabitat.org/content.as p?typeid $=19 \&$ catid $=555 \&$ cid $=9272-$ acessado em 12 de outubro de 2012.

\section{Notas}

1 A terceira Conferência das Partes de 1997 COP3, reunião de discussão da implentação da Convenção do Clima, estabeleceu que a maior contribuição de gases efeito estufa-GEE advém de cidades e países desenvolvidos, atribuindo apenas aos países ricos a reponsabilidade de reduzir em $5 \%$ os niveis de emissão existentes em 1990. Para tanto, o chamado Protoloco de Kyoto definiu 3 tipos de estratégias - redução, adaptação e mitigação e mecanismos finaceiros de implementação. 0 Mecanismo de Desenvolvimento Limpo- MDL é um destes mecanismos que permite que projetos para redução de emissões em países em desenvolvimento recebam certificados das suas reduções de emissões de GEE. Estes certificados podem ser vendidos ou trocados com outros países, sejam desenvolvidos ou em desenvolvimento.

20 conceito ampliado de tecnologia é discutido em Tecnologias Apropriadas para Saneamento Básico, de Fernando Tudela, São Paulo, FAUUSP, 1982.

$3 \mathrm{O}$ estudo de Thomas Kuhn, A estrutura das Revoluções Científicas, é o texto que trouxe à tona o uso do conceito de paradigma nos anos 1970/80, aplicado à história do fazer científico.

$4 \mathrm{O}$ assunto é discutido em ALVA, E.: Tecnologias apropriadas produção de bens e serviços; e em TUDELA, F.: Tecnologias Apropriadas para Saneamento Básico.

5 Rutkowski, Emilia in www.unicamp.academia. edu/documents.

6 Para estimar a composição e o quantitativo do biogás a ser produzido no aterro, pode ser utilizado o modelo matemático do Intergovernmental Panel on Climate Change (IPCC) - Waste Model, disponível no sítio eletrônico: http:// cdm.unfccc.int/index.html

7 ReCESA, BH, 2008 Esgotamento sanitário: operação manutenção de sistemas simplificados de tratamento.

8 Decisão tomada na Conferência do Clima em Durban, na África do Sul, em dezembro de 2011. 
9 De acordo com mapeamento da Secretaria de Estado da Defesa Civil do Distrito Federal, 2011, http://www.defesacivil.df.gov.br/.

10 Este plano foi contratado, e é um instrumento de gestão da ADASA- Agência Reguladora de Águas, Energia e Saneamento Básico do Distrito Federal.

11 Esta situação é percebida pelas matérias de jornais locais. pelos diversos diagnósticos dos estudos elaborados no Distrito Federal como: Plano Diretor, Eias/Rimas de empreendimentos, Zoneamento Econômico-Ecológico - ZEE, e o próprio estudo realizado para o Plano Diretor de Resíduos que não foi tranformado em legislação.

12 A coleta domiciliar de lixo no DF cobre todo o território e o destino final conta com duas estações de tratamento: uma implantada na década de 1960, que está desativada e possui uma pequena operação por catadores; e outra implantada na década de 1980 , que opera cerca de 600 ton/dia com grande volume de descarte que é depositado no aterro controlado.

13 Sobre o assunto, ler The Experience of Condominial Water and Sewerage Systems in Brazil: Case Studies from Brasilia, Salvador and Parauapebas, Worl Bank, 2005

14 O Projeto não foi elaborado pelo órgão gestor de resíduos, o Serviço de Limpeza Urbana SLU, mas por meio do Programa Brasilia Sustentável, apoiado pelo Banco Mundial.

15 Conestoga-Rovers \& Associates (2008) Pre-Feasibility study for the preparation of landfill gas projects in Latin America and the Caribbean, working paper s/n, Canada.

16 Valor da tonelada de carbono no mercado em 2009, época de elaboração do projeto em análise. 